\title{
ATRIBUT DESTINASI YANG MEMPENGARUHI LOYALITAS WISATAWAN BERKUNJUNG KE KAWASAN SANUR
}

\author{
Ni Luh Ayu Nusantini \\ Email: ayunusantini1@gmail.com
}

\begin{abstract}
Sanur is one of the most attractive and renowned beach tourist destinations in Bali. However, there is no particular study so far to determine the influential attributes on Sanur, as well as the factors which affecting tourist' opinion to visit this area. The purposes of this research are to determine the dominant attributes to determine visitors' perception toward tourism attributes, to determine tourist loyalty on visiting Sanur area. This research was conducted by interviewing 100 domestic and foreign visitors who reside in the area at the time of research by accidental sampling method. Information regarding the trend of the visitors was gathered from ten respondents including business owners and local tourist authority by purposive sampling method. The research found that factors which dominantly influent tourist' perception are ambience, beauty of scenery and accessibility. The ambience as the highest mean score, while the value of sport and outdoor activities is the lowest. The interest of both domestic and international tourist has been constantly high, where recommendation commitment is more preferable compared to other dimension (repurchasing and branding commitment).
\end{abstract}

Keywords: Perception, Tourism Attribute, Visiting Loyalty, Sanur Area.

\section{Pendahuluan}

Sektor pariwisata di Bali berkembang dengan pesat. Bali merupakan daerah tujuan wisata yang terkenal di dunia, yang sekaligus menjadi salah satu potensi utama untuk mengangkat citra Indonesia di mata internasional. Hampir semua kawasan di Bali memiliki potensi wisata yang merata, akan tetapi kawasan tujuan wisata di Bali umumnya terpusat di daerah dengan ciri khas wisata bahari antara lain Pantai Kuta, Pantai Sanur dan Pantai Dreamland dan sekitarnya. Sesuai dengan Peraturan Pemerintah Republik Indonesia Nomor 50 Tahun 2011, ditetapkan delapan puluh delapan (88) KSPN di seluruh Indonesia untuk tahun 2010 sampai dengan tahun 2025. Di Bali ditetapkan sebelas KSPN antara lain Sanur - Nusa Dua - Kuta, Bali 
Utara/Singaraja, Karangasem - Amuk, Menjangan - Pemuteran, Taman Nasional Bali Barat, Tulamben - Amed, Bedugul, Nusa Penida, Ubud dan Besakih - Gunung Agung.

Sanur merupakan salah satu ikon pariwisata Bali yang sudah dikenal sejak sebelum kemerdekaan. Kawasan Pantai Sanur sudah mulai dikunjungi sejak 1930 (Picard, 2006). Menetapnya pelukis Belgia bernama Adrien-Jean Le Mayeur de Merpres di Sanur merupakan sejarah perkembangan kawasan pesisir Sanur, karena lukisan dan keberadaan Museum Le Mayeur menjadi salah satu hal yang mengangkat nama Sanur di mata internasional. Sesuai data yang diperoleh dari Dinas Pariwisata Kota Denpasar dan data bersumber dari Polisi Sektor (Polsek) Denpasar, pada triwulan I tahun 2014, jumlah wisatawan yang menginap di berbagai penginapan baik hotel berbintang, hotel melati, villa dan lain sebagainya di kawasan Sanur mencapai 835.099 orang, naik dibandingkan triwulan I tahun 2013 yang berjumlah 727.013 orang. Peningkatan ini adalah tanda popularitas Sanur.

Hal ini sejalan program Kawasan Strategis Pariwisata Nasional (KSPN) dengan target pencapaian 3 juta wisatawan di tahun $2015 .{ }^{1}$ Dilihat dari potensi yang dimiliki Kawasan Sanur sebagai Daerah Tujuan Wisata (DTW) sudah sepantasnya Sanur menjadi pusat dari kegiatan wisata bahari yang paling populer dibandingkan dengan objek lainnya.

Peningkatan kunjungan wisatawan inilah yang mendasari keinginan untuk mengevaluasi persepsi wisatawan mengenai atribut destinasi wisata di Sanur yang berpengaruh pada pemenuhan keinginan wisatawan. Kawasan pesisir Sanur memiliki potensi yang baik dan memiliki berbagai macam jenis kegiatan wisata bahari yang mampu menarik motivasi wisatawan. Melihat potensi yang besar dari Pantai Sanur, tentunya merupakan hal penting untuk mengetahui hal-hal yang mendasari loyalitas berkunjung dari wisatawan akan Daerah Tujuan Wisata Kawasan Sanur itu sendiri. Lovelock, Paterson, dan Walker (2001) menjelaskan bahwa kesetiaan atau loyalitas sebagai sebuah evaluasi setelah pembelian oleh pelanggan mengenai pengalaman (proses serta hasil) dari pelayanan secara menyeluruh yang diterimanya. Kesetiaan muncul karena adanya atribut-atribut yang melekat pada obyek. Atribut dapat berupa dimensi jasa atau apa saja yang dipertimbangkan dalam keputusan untuk membeli produk wisata tersebut (Darmaningsih, dkk., 2006).

Kozak dan Rimington (1999) mengemukakan bahwa menentukan atribut dominan destinasi wisata sangat penting untuk mengukur tingkat kepuasan keseluruhan wisatawan sehingga memunculkan intensi untuk datang kembali ke daerah tujuan wisata tersebut. Telah dilakukan beberapa penelitian untuk mengukur atribut destinasi dan motivasi wisatawan seperti dalam penelitian

http:/travel.kompas.com/read/2014/11/08/16503327/wisatawan-ke-bali-akan-meningkat), diakses 8 Agustus 2014. Wisatawan ke Bali Akan Meningkat 
yang dilakukan oleh Meng, Tepanon, dan Uysal dalam jurnal mereka yang berjudul Measuring Tourist Satisfaction by Attribute and Motivation: The Case of Nature-Based Resort (2006). Disebutkan bahwa atribut destinasi wisata memiliki peran penting dalam evaluasi wisatawan atas daya tarik, image, dan kepuasan terhadap destinasi wisata tertentu.

Hingga saat ini belum ada studi terkait untuk mengukur atribut yang dominan pada destinasi wisata Kawasan Sanur dan loyalitas berkunjung wisatawan atas atribut Kawasan Sanur, yang nantinya dapat menjadi tolok ukur pengembangan dan penyusunan strategi pemasaran kawasan tersebut. Oleh karena itu, perlu dilakukan penelitian tentang atribut destinasi wisata Kawasan Sanur terhadap loyalitas berkunjung wisatawan, yang pada akhirnya dapat mendukung pengembangan kawasan Sanur sebagai salah satu destinasi favorit di Indonesia. Artikel ini diharapkan dapat memberikan kontribusi pengetahuan mengenai model pariwisata dari segi-segi yang menentukan kesetiaan wisatawan secara komprehensif. Secara khusus artikel ini disusun untuk menjawab pertanyaan-pertanyaan berikut: Atribut apa saja yang berperan dominan dalam mempengaruhi loyalitas berkunjung wisata ke Kawasan Sanur? Bagaimana persepsi wisatawan terhadap atribut wisata Kawasan Sanur? dan Bagaimana loyalitas berkunjung wisatawan terhadap destinasi wisata Kawasan Sanur?

\section{Teori dan Metode Penelitian}

Kajian pustaka yang digunakan dalam artikel ini adalah persepsi wisatawan, atribut wisata, penawaran wisata, kepuasan wisatawan dan loyalitas wisatawan. Wisatawan adalah mereka yang melakukan kunjungan wisata ke suatu daerah tujuan wisata baik wisatawan domestik maupun mancanegara. Wisatawan yang disasar sebagai responden dalam penelitian ini adalah wisatawan yang berkunjung dengan pengalaman kunjungan minimal satu kali sebelumnya.

Walgito (2002) mengemukakan bahwa persepsi wisawatan sebagai suatu proses dimana wisatawan mengartikan stimulus yang diterima melalui inderanya menjadi suatu makna, yang dipengaruhi pula oleh masa lalu wisatawan tersebut. Rangkuti (2003) menyebutkan bahwa persepsi wisatawan dipengaruhi oleh tiga hal utama yaitu tingkat kepentingan wisatawan, yang didefinisikan sebagai keyakinan wisatawan sebelum mencoba atau membeli produk atau jasa, yang akan dijadikan standar acuan dalam menilai kinerja produk atau jasa tersebut, kepuasan wisatawan yang didefinisikan sebagai respon pelanggan terhadap ketidaksesuaian antara tingkat kepentingan sebelumnya (harapan) dan kinerja aktual yang dirasakannya (persepsi) serta nilai didefinisikan sebagai pengkajian secara menyeluruh manfaat dari suatu produk yang didasarkan pada persepsi wisatawan atas apa yang telah diterima oleh wisatawan dan yang telah 
diberikan oleh produk tersebut.

Dann (1977) menegaskan bahwa ada hubungan yang jelas antara faktor pendorong dan faktor penarik wisatawan untuk mengunjungi suatu destinasi wisata. Faktor pendorong adalah motivasi, keinginan, kebutuhan, dan persepsi mempengaruhi wisatawan, sedangkan faktor penarik adalah atribut destinasi. Atribut dapat berupa dimensi jasa atau apa saja yang dipertimbangkan dalam keputusan untuk membeli produk wisata tersebut (Darmaningsih, dkk., 2006). Kozak dan Rimington (2000) mengemukakan bahwa menentukan atribut dominan destinasi wisata sangat penting untuk mengukur tingkat kepuasan keseluruhan wisatawan. Zhou dalam penelitiannya yang berjudul Destination Attributes that Attract International Tourists to Cape Town (2005), yakni keindahan alam (the beauty of scenery), budaya dan sejarah (culture and history), suasana (ambience), aksesibilitas (accessibility), keamanan (safety), biaya (price), pelayanan (services), olahraga dan aktivitas luar (sport and outdoor activities).

Seperti halnya pariwisata bahari pantai lainnya, kawasan Sanur tidak akan berkembang jika hanya memiliki daya tarik saja, harus ada aspek-aspek lainnya yang mendukung sehingga pariwisata bahari dapat berkembang dengan baik. Menurut Medlik, 1980 (dalam Ariyanto 2005), ada empat aspek (4A) yang harus diperhatikan dalam penawaran pariwisata yaitu attraction (daya tarik), accesable (transportasi), amenities (fasilitas) dan ancillary (kelembagaan).

Lovelock, dkk.(2007) menyatakan bahwa loyalitas adalah suatu kesediaan wisatawan untuk melanjutkan aktivitas terhadap suatu produk wisata dalam jangka waktu yang panjang dan melakukan aktivitas secara berulang, serta merekomendasinya kepada teman-teman lain secara sukarela. Indikator pengukuran loyalitas wisatawan yakni pembelian ulang (buyer's repetition) (Parasuraman, dkk., 1988; Schmid, 1997; Paliati, 2007) yaitu pembelian yang dilakukan secara terus menerus terhadap produk wisata yang telah dikonsumsi; komitmen merek (Dick dan Basu, 1994) yaitu komitmen yang kuat pada produk wisata tersebut, tidak memiliki keinginan untuk berpindah ke produk wisata lainnya serta berusaha untuk meneruskan aktivitas tindakan terhadap produk wisata itu kembali; getok tular positif atau rekomendasi (Morgan dan Hunt, 1994; Dick dan Basu, 1994; Paliati; 2007) yaitu merekomendasikan produk yang telah dikonsumsi kepada teman serta mengemukakan hal-hal positif mengenai pengalamannya saat menikmati produk wisata.

Lovelock, Paterson, dan Walker (2001) berpendapat bahwa kesetiaan atau loyalitas timbul sebagai sebuah evaluasi setelah pembelian oleh pelanggan mengenai pengalaman (proses serta hasil) dari pelayanan secara menyeluruh yang diterimanya. Kesetiaan timbul setelah konsumen puas 


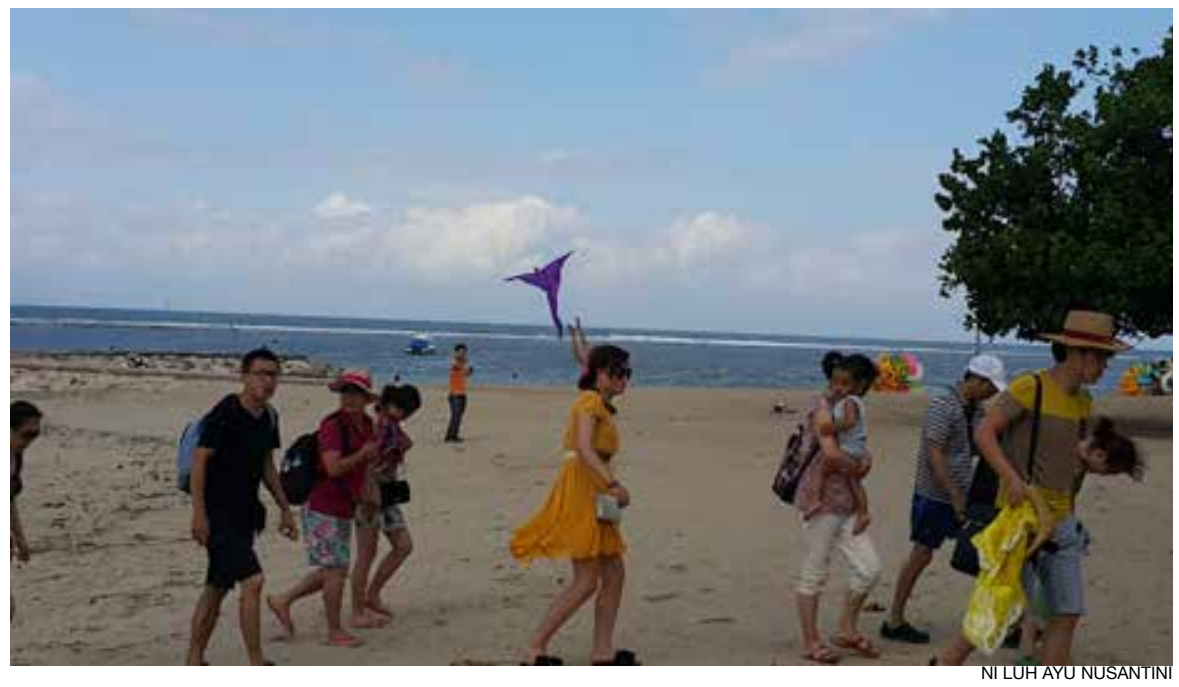

Foto 1. Wisatawan Mancanegara di Pantai Sanur.

akan sebuah pengalaman, sehingga akan timbul pembelian ulang atau keinginan untuk mengalami hal tersebut secara berulang. Kesetiaan akan menghasilkan word of mouth yang dapat mempengaruhi wisatawan lain. Kesetiaan ini dapat mempengaruhi wisatawan untuk berkunjung kembali ke Kawasan Sanur (Foto 1 dan 2). Atribut yang melekat pada objek akan memunculkan kesetiaan itu sendiri. Hal ini dijelaskan oleh Darmaningsih, dkk. (2006) bahwa atribut yang melekat tersebut dapat berupa dimensi jasa atau apa saja yang dipertimbangkan dalam keputusan untuk membeli produk wisata tersebut.

Hal yang serupa juga disebutkan oleh Kozak dan Rimington (1999) bahwa menentukan atribut dominan destinasi wisata sangat penting untuk mengukur tingkat kepuasan keseluruhan wisatawan sehingga memunculkan intensi untuk datang kembali ke daerah tujuan wisata tersebut. Telah dilakukan beberapa penelitian untuk mengukur atribut destinasi dan motivasi wisatawan seperti dalam penelitian yang dilakukan oleh Meng, Tepanon, dan Uysal (2006). Disebutkan bahwa atribut destinasi wisata memiliki peran penting dalam evaluasi wisatawan atas daya tarik, image, dan kepuasan terhadap destinasi wisata tertentu.

Artikel ini menggunakan pendekatan kuantitatif yang didukung dengan pendekatan kualitatif. Dilakukan dengan menggunakan empat teknik pengumpulan data, yaitu: pengamatan terhadap wisatawan, pelaku wisata di Kawasan Sanur, penyebaran kuesioner, wawancara mendalam dan studi dokumentasi. Data kuantitatif yang didapat dari penyebaran kuesioner, diukur dengan menggunakan skala Likert dengan kontinum lima poin, bobot $5,4,3,2,1$. Indikator atau variabel yang terukur dijadikan titik tolak 


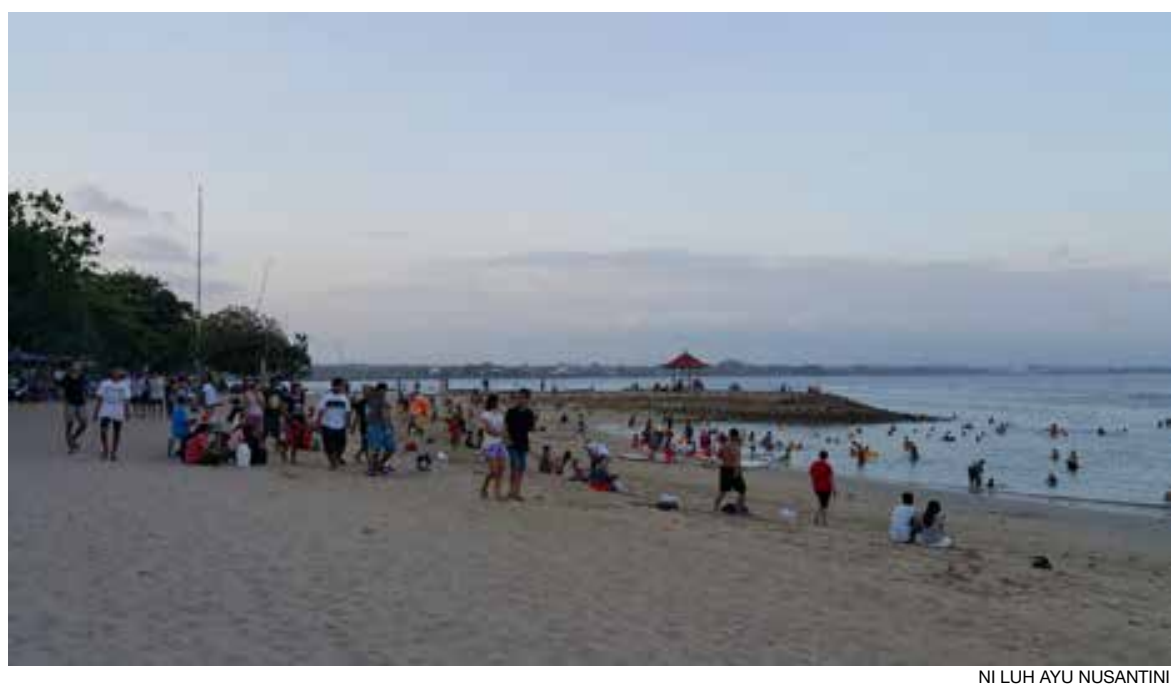

Foto 2. Wisatawan Domestik di Pantai Sanur.

berupa pertanyaan atau pernyataan yang perlu dijawab oleh responden.

Berdasarkan teori loyalitas wisatawan terdapat tiga indikator pengukuran loyalitas yaitu pembelian ulang (buyer's repetition) (Parasuraman, dkk., 1988; Schmid, 1997; Paliati, 2007), komitmen Merek (Dick dan Basu, 1994), getok Tular Positif/Rekomendasi (Morgan dan Hunt, 1994; Dick dan Basu, 1994; Paliati; 2007). Sedangkan delapan faktor atribut wisata yang mempengaruhi persepsi sesuai dengan penelitian Zhou (2005), yaitu the beauty of scenery ( $\mathrm{F} 1)$, culture and history (F2), ambience ( $\left.\mathrm{F}_{3}\right)$, accessibility (F4), safety (F5), price (F6), services (F7), sport and outdoor activities (F8). Pengukuran persepsi terhadap atribut wisata dibentuk oleh empat variabel dari F1, empat variabel dari F2, tiga variabel dari F3, empat variabel dari F4, tiga variabel dari $\mathrm{F}_{5}$, lima variabel dari F6, empat variabel dari $\mathrm{F}_{7}$ dan tiga variabel dari F8.

Penelitian dilakukan di kawasan Sanur mulai bulan Mei sampai dengan Juni 2015. Populasi dalam penelitian ini adalah wisatawan yang berada di kawasan Sanur. Wisatawan yang dimaksud adalah wisatawan domestik maupun mancanegara yang berkunjung ke kawasan Sanur, dengan pengalaman kunjungan minimal satu kali sebelumnya. Jumlah total responden adalah 100 dengan menggunakan rumus Slovin. Pengambilan responden berdasarkan teknik accindental sampling. Sedangkan penentuan informan yang dalam penelitian ini adalah pelaku dan pengamat wisata termasuk pemerintah digunakan teknik purposive sampling.

Hasil analisis diuraikan dengan narasi deskriptif kuantitatif berdasarkan hasil analisis faktor-faktor yang memengaruhi persepsi wisatawan terhadap atribut wisata Kawasan Sanur menggunakan teknik analisis faktor dengan 
software SPSS 20. Hasil analisis kuantitatif juga didukung oleh wawancara mendalam kepada wisatawan, pengelola hotel, cafe dan restoran serta pemerintah setempat menggunakan teknik analisis desriptif kualitatif.

\section{Hasil dan Pembahasan}

\subsection{Karakteristik Responden}

Jumlah responden yang digunakan sebanyak 100 orang. Responden yang merupakan wisatawan domestik sebanyak 50 orang dan wisatawan mancanegara sebanyak 50 orang. Tabel 1 menunjukkan data distribusi responden.

Tabel 1 Distribusi Karakteristik Responden

\begin{tabular}{|c|c|c|c|}
\hline \multirow[b]{2}{*}{ Identitas Diri } & \multirow[b]{2}{*}{ Distribusi Responden } & \multicolumn{2}{|c|}{ Jumlah } \\
\hline & & Orang & Persentase \\
\hline \multirow[t]{3}{*}{ Jenis Kelamin } & Laki-laki & 51 & 51,00 \\
\hline & Perempuan & 49 & 49,00 \\
\hline & Jumlah & 100 & 100 \\
\hline \multirow{5}{*}{$\begin{array}{l}\text { Kelompok Umur } \\
\text { (Tahun) }\end{array}$} & $<20$ & 7 & 7,00 \\
\hline & $21-40$ & 59 & 59,00 \\
\hline & $41-60$ & 28 & 28,00 \\
\hline & $61-80$ & 6 & 6,00 \\
\hline & Jumlah & 100 & 100 \\
\hline \multirow[t]{13}{*}{ Pekerjaan } & Wiraswasta/Pengusaha & 23 & 23,00 \\
\hline & Karyawan Swasta & 21 & 21,00 \\
\hline & Pelajar/Mahasiswa & 15 & 15,00 \\
\hline & Pensiunan & 10 & 10,00 \\
\hline & Nelayan & 5 & 5,00 \\
\hline & Guru & 4 & 4,00 \\
\hline & Pegawai BUMN & 3 & 3,00 \\
\hline & PNS & 3 & 3,00 \\
\hline & Perawat & 3 & 3,00 \\
\hline & Buruh & 2 & 2,00 \\
\hline & IRT & 2 & 2,00 \\
\hline & Profesional lainnya & 9 & 9,00 \\
\hline & Jumlah & 100 & 100 \\
\hline \multicolumn{4}{|l|}{ Daerah Asal } \\
\hline \multirow[t]{9}{*}{ Domestik } & Jawa Timur & 16 & 32,00 \\
\hline & Jakarta & 12 & 24,00 \\
\hline & Jawa Tengah & 7 & 14,00 \\
\hline & Jawa Barat & 5 & 10,00 \\
\hline & Palembang & 4 & 8,00 \\
\hline & Manado & 3 & 6,00 \\
\hline & NTB & 2 & 4,00 \\
\hline & Maluku & 1 & 2,00 \\
\hline & Jumlah & 50 & 100 \\
\hline
\end{tabular}




\begin{tabular}{|c|c|c|c|}
\hline \multirow[t]{6}{*}{ Mancanegara } & Australia & 17 & 34,00 \\
\hline & Belanda & 15 & 30,00 \\
\hline & Amerika & 10 & 20,00 \\
\hline & Asia Timur & 8 & 16,00 \\
\hline & Jumlah & 50 & 100,00 \\
\hline & Jumlah total & 100 & 100 \\
\hline \multirow[t]{5}{*}{ Jumlah Kunjungan } & 2-3 kali & 60 & 60,00 \\
\hline & 4-5 kali & 31 & 31,00 \\
\hline & 6-7 kali & 5 & 5,00 \\
\hline & 8-9 kali & 1 & 1,00 \\
\hline & $\begin{array}{l}10< \\
\text { Jumlah }\end{array}$ & $\begin{array}{c}3 \\
100\end{array}$ & $\begin{array}{c}3,00 \\
\mathbf{1 0 0 , 0 0}\end{array}$ \\
\hline
\end{tabular}

Sumber : Hasil Pengolahan Data, 2015

\subsection{Faktor Dominan Pembentuk Persepsi Wisatawan terhadap Atribut Destinasi Kawasan Sanur}

Hasil analisis faktor persepsi terhadap atribut wisata di Kawasan Sanur merupakan gabungan skor faktor delapan faktor yaitu: keindahan alam (F1); budaya dan sejarah (F2); suasana (F3); aksesibilitas (F4); keamanan ( 55 ); biaya (F6); pelayanan (F7) serta aktivitas luar dan olahraga (F8). Mengacu pada hasil analisis faktor didapat nilai KMO sebesar o,837 ini berarti bahwa KMO > 0,5 dengan nilai Sig < 0,05; yang berarti bahwa semua faktor layak untuk difaktorkan (Tabel 2). Jadi, dengan nilai KMO o,837 dan nilai Sig o,00o (nilai sig < 0,05) seperti terlihat pada Tabel 2, menyatakan bahwa faktor persepsi wisatawan terhadap atribut wisata di Kawasan Sanur memang benar ditentukan oleh delapan faktor yaitu keindahan alam (F1), budaya dan sejarah (F2), suasana (F3), aksesibilitas (F4), keamanan (F5), biaya (F6), pelayanan (F7) serta aktivitas luar dan olahraga (F8). Tabel 2 Hasil Uji KMO and Bartlett's Faktor Persepsi Wisatawan terh dap Atribut Wisata

Tabel 2 Hasil Uji KMO and Bartlett's Faktor Persepsi Wisatawan terh dap Atribut Wisata

\begin{tabular}{llr}
\hline Kaiser-Meyer-Olkin Measure of Sampling Adequacy. & .837 \\
\hline Bartlett's Test of Sphericity & Approx. Chi-Square & 206.535 \\
& Df & 10 \\
& Sig. & .000 \\
\hline
\end{tabular}

Sumber: Hasil Pengolahan Data, 2015

Hasil analisis anti image correlation antar faktor (F1 sampai dengan F8) sebagai faktor pembentuk faktor persepsi wisatawan terhadap atribut wisata disajikan dalam Tabel 3. Dapat dilihat bahwa faktor F1 sampai dengan F8 secara statistik mempunyai korelasi yang sangat signifikan dengan nilai anti image correlation lebih dari 0,5 . 
Tabel 3 Matrik Korelasi Antar Variabel Pembentuk Faktor Persepsi Wisatawan terhadap Atribut Destinasi

\begin{tabular}{llllllllll}
\hline & $\begin{array}{c}\text { Fak- } \\
\text { tor }\end{array}$ & F1 & F2 & F3 & F4 & F5 & F6 & F7 & \multicolumn{1}{l}{ F8 } \\
\hline Anti-image & F1 & $.831^{\mathrm{a}}$ & -.415 & -.124 & -.195 & .060 & -.317 & -.194 & -.216 \\
Correlation & F2 & -.415 & $.798^{\mathrm{a}}$ & -.383 & -.197 & -.090 & -.223 & -.081 & -.107 \\
& F3 & -.124 & -.383 & $.836^{\mathrm{a}}$ & -.234 & -.216 & -.245 & -.546 & -.205 \\
& $\mathrm{~F} 4$ & -.195 & -.197 & -.234 & $.876^{\mathrm{a}}$ & -.193 & -.084 & -.389 & .191 \\
& $\mathrm{~F} 5$ & .060 & -.090 & -.216 & -.193 & $.871^{\mathrm{a}}$ & -.238 & -.110 & -.346 \\
& $\mathrm{~F} 6$ & -.317 & -.223 & -.245 & -.084 & -.238 & $.782^{\mathrm{a}}$ & -.170 & -.352 \\
& F7 & -.194 & -.081 & -.546 & -.389 & -.110 & -.170 & $.831^{\mathrm{a}}$ & -455 \\
& F8 & -.216 & -.107 & -.205 & .191 & -.346 & -.352 & -455 & $.655^{\mathrm{a}}$ \\
\hline
\end{tabular}

Pengaruh dari setiap variabel pembentuk faktor terhadap faktor dapat diketahui dari nilai komunalitasnya, dapat terlihat pada Tabel 4 . Dengan nilai komunalitas menunjukkan persentase masing-masing faktor pembentuk persepsi wisatawan terhadap atribut destinasi wisata yang dapat diterangkan oleh faktor yang terbentuk, seperti faktor suasana (F3) angka komunalitasnya adalah o,857. Ini berarti sekitar $85,7 \%$ varians dari faktor suasana bisa dijelaskan oleh faktor yang terbentuk; dan faktor keindahan alam (F1) menunjukkan angka adalah o,816. Ini berarti sekitar $81,6 \%$ varians dari faktor keindahan alam bisa dijelaskan oleh faktor yang terbentuk. Demikian seterusnya untuk faktor lainnya, dengan ketentuan bahwa semakin besar communalities sebuah faktor, berarti semakin erat hubungannya dengan faktor yang terbentuk.

Tabel 4 Komunalitas Variabel-variabel Faktor Persepsi Wisatawan terhadap Atribut Destinasi Wisata

\begin{tabular}{lcc}
\hline & Initial & Extraction \\
\hline F1 (Keindahan Alam) & 1.000 & .816 \\
F2 ( Budaya dan Sejarah) & 1.000 & .792 \\
F3 (Suasana) & 1.000 & .857 \\
F4 (Aksesibilitas) & 1.000 & .805 \\
F5 (Keamanan) & 1.000 & .748 \\
F6 (Biaya) & 1.000 & .729 \\
F7 (Pelayanan) & 1.000 & .785 \\
F8 (Olahraga dan Aktivitas Luar) & 1.000 & .739
\end{tabular}

Sumber : Pengolahan Data, 2015

Tabel 5 menunjukkan bahwa faktor persepsi terhadap atribut wisata dapat mewakili komponen pembentuknya sebesar $62,420 \%$ dari total varians, yang berarti bahwa terbentuk satu faktor yang mewakili delapan 
faktor pembentuk (F1 sampai dengan F8) dengan nilai akar ciri (eigenvalues) sebesar 3,309 lebih besar dari 1,00.

Tabel 5 Nilai Eigenvalues, Persentase Varians dan Persentase Kumulatif Varians dari Delapan Faktor Pembentuk Faktor Persepsi Wisatawan terhadap Atribut Destinasi

\begin{tabular}{|c|c|c|c|c|c|c|}
\hline \multirow{2}{*}{ Component- } & \multicolumn{3}{|c|}{ Initial Eigenvalues } & \multicolumn{3}{|c|}{$\begin{array}{l}\text { Extraction Sums of } \\
\text { Squared Loadings }\end{array}$} \\
\hline & Total & $\begin{array}{l}\% \text { of Vari- } \\
\text { ance }\end{array}$ & $\begin{array}{c}\text { Cumulative } \\
\%\end{array}$ & Total & $\begin{array}{l}\% \text { of Vari- } \\
\text { ance }\end{array}$ & $\begin{array}{c}\text { Cumulative } \\
\%\end{array}$ \\
\hline 1 & 3.309 & 62.42 & 62.42 & 3.309 & 62.42 & 62.42 \\
\hline 2 & 1.105 & 18.425 & $73 \cdot 517$ & 1.105 & 18.425 & 73.517 \\
\hline 3 & 0.754 & 9.752 & 78.463 & & & \\
\hline 4 & 0.524 & 8.731 & 82.302 & & & \\
\hline 5 & 0.444 & $7 \cdot 4$ & 89.707 & & & \\
\hline 6 & 0.403 & 6.851 & 92.345 & & & \\
\hline 7 & 0.345 & $5 \cdot 747$ & 95.449 & & & \\
\hline 8 & 0.273 & 4.551 & 100 & & & \\
\hline
\end{tabular}

Sumber: Pengolahan Data, 2015

Tabel 6 Matrik Faktor Persepsi Wisatawan terhadap Atribut Destinasi dengan Rotasi Varimax

\begin{tabular}{lc}
\hline \multicolumn{1}{c}{ Variabel } & Component \\
\hline F1 (Keindahan Alam) & .801 \\
F2 ( Budaya dan Sejarah) & .775 \\
F3 (Suasana) & .829 \\
F4 (Aksesibilitas) & .792 \\
F5 (Keamanan) & .713 \\
F6 (Biaya) & .685 \\
F7 (Pelayanan) & .743 \\
F8 (Olahraga dan Aktivitas Luar) & .694 \\
\hline
\end{tabular}

Sumber: Pengolahan Data, 2015

Hasil analisis komponen matrik seperti pada Tabel 6 menunjukan hubungan atau korelasi setiap faktor (F1 sampai F8) terhadap faktor yang terbentuk (Faktor Persepsi terhadap Atribut Wisata). Semakin tinggi nilai komponen matrik setiap faktor, maka semakin kuat hubungannya atau semakin besar pengaruhnya dalam pembentukan faktor persepsi wisatawan terhadap atribut wisata demikian juga sebaliknya. Berdasarkan Tabel 6 dapat diketahui bahwa faktor suasana (F3) mempunyai hubungan yang paling kuat terhadap faktor persepsi wisatawan terhadap atribut wisata di Kawasan Sanur (faktor persepsi terhadap atribut wisata) dengan koefisien korelasi o,829; dan hubungan paling lemah ditunjukkan oleh faktor biaya (F6) dengan koefisien korelasi o,685. 
Berdasarkan hasil analisis faktor gabung di atas dapat diinterpretasikan bahwa dari kedelapan faktor pembentuk persepsi wisatawan terhadap atribut wisata, faktor biaya harus mendapat perhatian paling besar terhadap faktor persepsi wisatawan terhadap atribut wisata, diikuti oleh variabel aktivitas olahraga dan aktivitas luar. Sedangkan yang harus dipertahankan adalah faktor suasana. Berdasarkan pengamatan langsung dan wawancara dengan wisatawan yang berkunjung hampir sebagian besar mengungkapkan alasan utama berkunjung ke kawasan sanur adalah mencari suasana yang tenang dan relaks yang kurang bisa didapatkan di kawasan pantai lainnya. Selain itu wisatawan juga mencari pemandangan alam pantai yang alami dengan pesona matahari terbit sebagai ciri khas utamanya.

\subsection{Persepsi Wisatawan terhadap Atribut Wisata KawasanSanur}

Secara umum persepsi wisatawan terhadap atribut wisata di Kawasan Sanur adalah positif dengan nilai rata-rata 3,78 (Tabel 7). Peringkat rata-rata faktor persepsi terhadap atribut wisata di Kawasan Sanur tertinggi sampai dengan terendah adalah sebagai berikut: faktor suasana dengan skor ratarata yang paling tinggi yaitu 4,12; dan faktor skor rata-rata terendah adalah faktor olahraga dan aktivitas luar dengan skor 3,51 (Tabel 7)

Tabel 7 Statistik Rata-Rata 30 Variabel Persepsi terhadap Atribut Kawasan Sanur

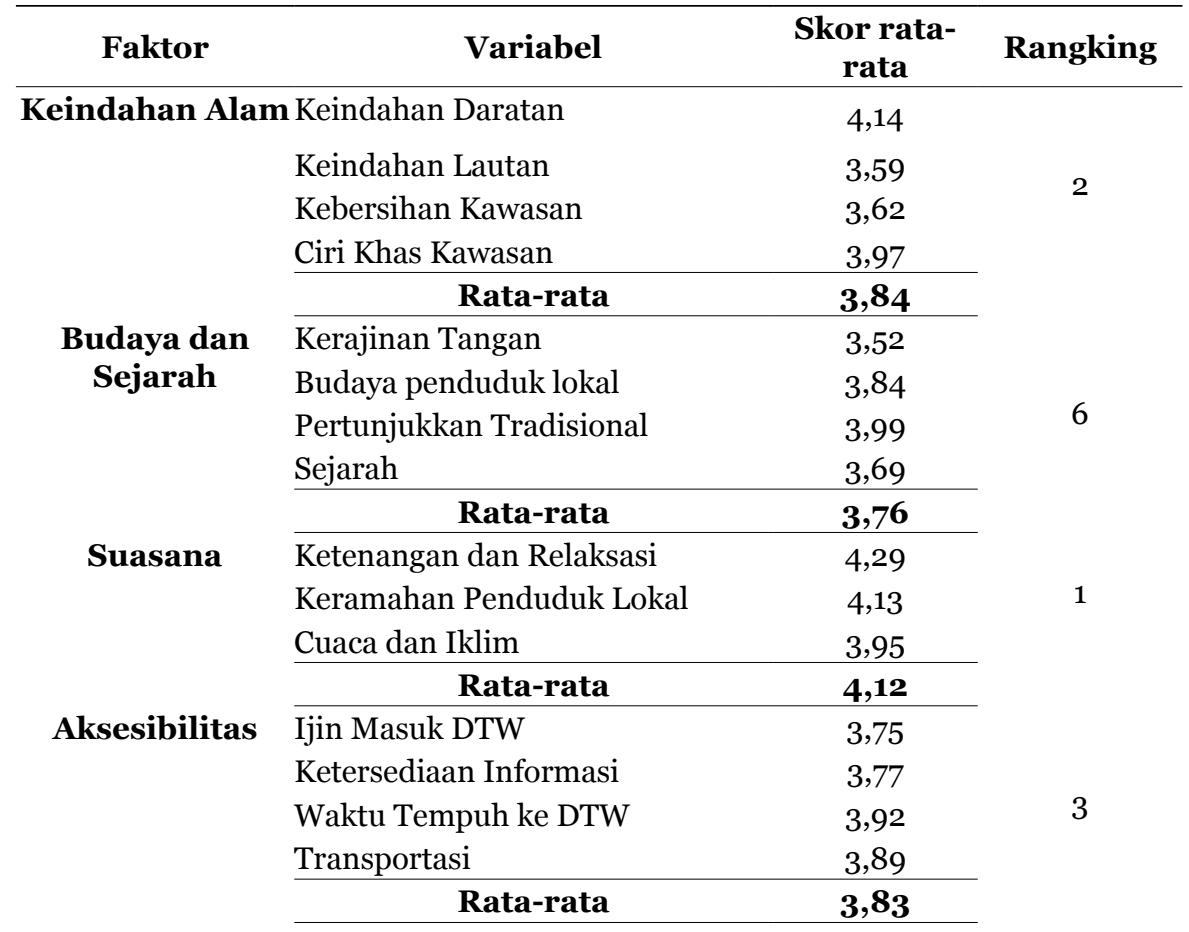




\begin{tabular}{|c|c|c|c|}
\hline \multirow[t]{4}{*}{ Keamanan } & Keamanan Area Publik & 3,56 & \multirow{3}{*}{5} \\
\hline & Keamanan Transportasi & 4,02 & \\
\hline & Keamanan Areal Wisata & 3,76 & \\
\hline & Rata-rata & 3,78 & \multirow{7}{*}{7} \\
\hline \multirow[t]{6}{*}{ Biaya } & Biaya Transportasi & 3,39 & \\
\hline & Biaya Menginap & 4,03 & \\
\hline & Biaya Bea Masuk Area Wisata & 3,67 & \\
\hline & Biaya Makanan & 3,86 & \\
\hline & Biaya Kerajinan Tangan & 3,52 & \\
\hline & Rata-rata & 3,69 & \\
\hline \multirow[t]{5}{*}{ Pelayanan } & Pelayanan Bandara & 3,66 & \multirow{5}{*}{4} \\
\hline & Pelayanan Akomodasi Hotel & 4,17 & \\
\hline & Pelayanan Restoran/Makanan & 4,04 & \\
\hline & Pelayanan Fasilitas Wisata & 3,34 & \\
\hline & Rata-rata & $\mathbf{3 , 8 0}$ & \\
\hline \multirow{4}{*}{$\begin{array}{l}\text { Olahraga dan } \\
\text { Aktivitas Luar }\end{array}$} & Aktivitas Diving & 3,33 & \multirow{4}{*}{8} \\
\hline & Aktivitas Snorkling & 3,45 & \\
\hline & Aktivitas Olahraga & 3,76 & \\
\hline & $\begin{array}{c}\text { Rata-rata } \\
\text { Rata-rata Umum }\end{array}$ & $\begin{array}{l}\mathbf{3 , 5 1} \\
\mathbf{3 , 7 8}\end{array}$ & \\
\hline
\end{tabular}

Sumber: Pengolahan Data, 2015

Beberapa pernyataan yang mendukung hasil penelitian ini, didapatkan melalui wawancara dengan wisatawan mancanegara yang terangkum sebagai berikut:

\section{Mike (USA)}

"I prefer to live here in the village of Matahari Terbit beach. Because here I can blend my self more to local people rather than I stay in the hotel. Here I can more understand about their simple life, cultures, activities and many more that I couldn't get in my country. Sanur for me is like my second home. Every year I spent my vacation in Sanur. I choose Bali especially Sanur because Sanur has a good atmosphere to relax, has nice and friendly local people that can help you any time, and also a quiet place. Sanur is totally different than Kuta or Seminyak.

Lebih jauh, Mike menyampaikan:

In general, I think Sanur is so ready for people or tourist who wants to have a quite feelings during their vacation. There are so many hotels from bungalow to five stars, so many eating places that you could choose depends on your pocket, and so many more for tourists demand. I notice, Sanur is become growing and better. Short word.....I love Sanur" 
Mike mengungkapkan bahwa ia lebih memilih tinggal di perkampungan di Pantai Matahari Terbit karena ia jadi bisa berbaur dengan masyarakat lokal. Ia juga bisa lebih mengerti akan kesederhanaan hidup penduduk lokal, budaya dan lain sebagainya yang tidak dapat di temui di Negara asalnya. Ia merasa bahwa Sanur menjadi rumah kedua. Setiap tahun ia pasti berlibur ke Sanur. Ia memilih Sanur karena memiliki suasana yang bagus untuk rileks, masyarakatnya ramah dan tempatnya tenang berbeda dengan dengan Kuta dan Seminyak.

Secara umum menurutnya Sanur sangat siap untuk wisatawan yang meninginkan rasa dan suasana tenang selama liburannya. Banyak hotel dari bungalow sampai bintang lima, banyak tempat makan dengan berbagai pilihan sesuai isi dompetmu, dan banyak lagi sesuai dengan kebutuhan wisatawan. Ia juga mencatat Sanur saat ini lebih berkembang dan baik. Secara singkat ia mengatakan bahwa ia mencintai Sanur.

\section{Anna \& Beatrix (Australia)}

"I'm from Australia. I stay here in Sanur with my family. I stay in hotel. I knew Sanur from my friend Beatrix. She has been live in Sanur for years. She recommends me to live in Sanur because I want to have a quite place to stay rather than other places. You can find anything you want so easily. Anything that related to tourism is there. I visit Sanur for couple times. Usually once a year for weeks."

Ana mengatakan berasal dari Australia. Ia tinggal di Sanur bersama keluarga. Ia tinggal di hotel dan mengetahui Sanur dari teman baiknya Beatrix yang sudah tinggal di Sanur selama bertahun-tahun. Dia merekomendasikan untuk tinggal di Sanur dibandingkan tempat lain karena ia ingin mencari tempat yang tenang. Anda bisa mendapatkan segalanya disini dengan mudah. Semua yang berkaitan dengan kebutuhan wisatawan ada di sini. Ia sudah mengunjungi Sanur beberapa kali, biasanya setahun sekali selama beberapa minggu.

Kedua responden yang merupakan wisatawan asing kurang lebih menyatakan bahwa tujuan mereka memilih Sanur dibandingkan pantai lainnya tidak lain karena suasana tenang dan penerimaan masyarakat lokal yang sangat hangat terhadap mereka. Sanur juga dinilai sudah sangat siap untuk dikunjungi dengan berbagai fasilitas yang sangat lengkap dan telah memenuhi kebutuhan para wisatawan. Perkembangan Sanur menurut mereka sudah semakin baik dan perlu dipertahankan. Semua kesan dan penilaian dari wisatawan tersebut hendaknya dapat menjadi perhatian bagi pemerintah, pelaku wisatawan juga masyarakat lokal untuk menjaga penilaian juga kepercayaan wisatawan tersebut dan semakin menjaga keberlangsungan (sustainable) baik alam dan atribut wisata yang ada di Kawasan Sanur (Foto 3). 


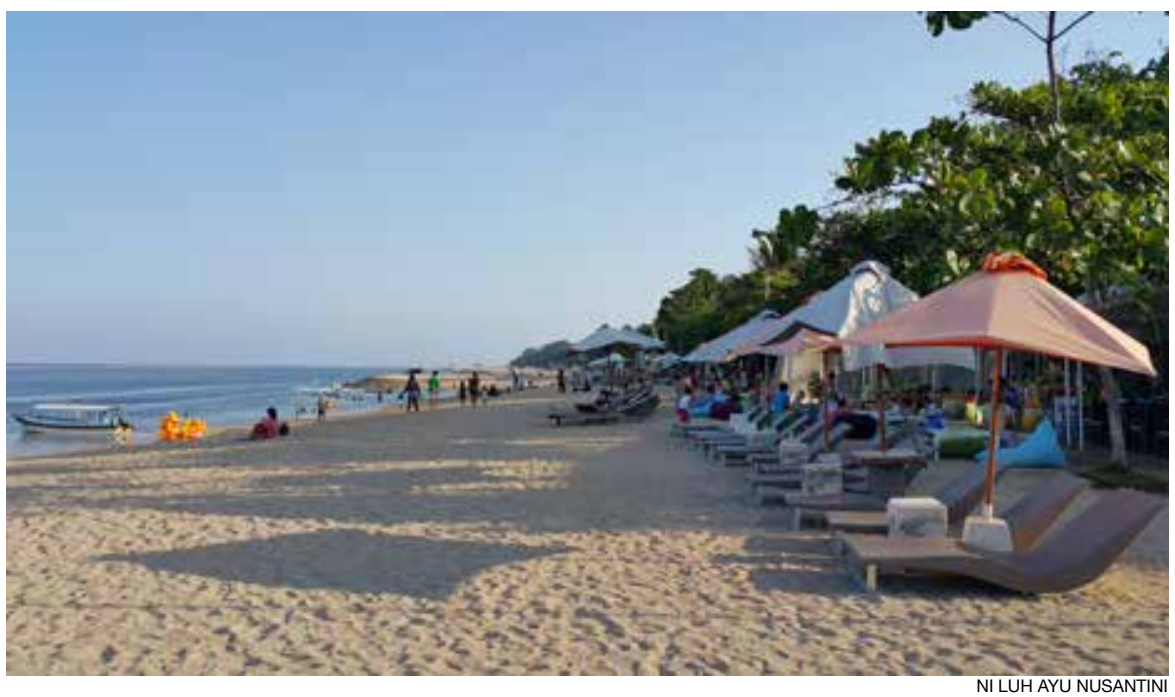

Foto 3. Suasana tenang dan keindahan kawasan Sanur.

\subsection{Loyalitas Berkunjung Wisatawan ke Kawasan Sanur}

Secara umum loyalitas berkunjung wisatawan domestik terhadap Kawasan Sanur berada pada tingkat tinggi dengan nilai rata-rata 4,01. Hal ini menunjukkan bahwa loyalitas berkunjung wisatawan domestik pada dimensi rekomendasi atau getok tular lebih besar dibandingkan dimensi pembelian ulang maupun komitmen merek. Sedangkan loyalitas berkunjung wisatawan mancanegara ke Kawasan Sanur berada pada tingkat tinggi dengan nilai rata-rata 3,75. Hal ini menunjukkan bahwa loyalitas berkunjung wisatawan mancanegara pada dimensi rekomendasi lebih besar dibandingkan dimensi komitmen merek maupun pembelian ulang (Tabel 8).

Terdapat empat variabel loyalitas berkunjung wisatawan domestik ke Kawasan Sanur yang berada pada tingkat sangat tinggi, enam pernyataan atau variabel loyalitas berkunjung wisatawan domestik yang berada pada tingkat tinggi dan dua variabel loyalitas berkunjung wisatawan domestik yang berada pada tingkat cukup atau sedang. Terdapat empat pernyataan atau variabel loyalitas berkunjung wisatawan domestik ke Kawasan Sanur yang berada pada tingkat sangat tinggi. Keempat variabel tersebut merupakan variabel pembentuk faktor getok tular atau rekomendasi yaitu rekomendasi verbal (Y3.1) dengan skor rata-rata 4,52, deskripsi pengalaman positif (Y3.4) dengan skor rata-rata sebesar 4,36, variabel ajakan untuk berlibur (Y3.2) dengan skor rata-rata sebesar 4,28 dan pernyataan keunggulan (Y3.3) dengan skor rerata sebesar 4,22.

Sedangkan pada loyalitas berkunjung wisatawan mancanegara ke Kawasan Sanur terdapat dua variabel pada tingkat sangat tinggi, delapan variabel loyalitas berkunjung wisatawan mancanegara yang berada pada 
tingkat tinggi dan dua variabel loyalitas berkunjung wisatawan mancanegara yang berada pada tingkat cukup atau sedang. Terdapat empat variabel loyalitas berkunjung wisatawan mancanegara ke Kawasan Sanur yang berada pada tingkat sangat tinggi. Kedua variabel tersebut merupakan variabel pembentuk faktor getok tular atau rekomendasi,yaitu rekomendasi verbal (Y3.1) dengan skor rata-rata tertinggi sebesar 4.40, dan pernyataan keunggulan (Y3.2) dengan skor rata-rata sebesar 4,24.

Tabel 8 Loyalitas Berkunjung Wisatawan Ke Kawasan Sanur

\begin{tabular}{|c|c|c|c|}
\hline Faktor & Variabel Pernyataan & $\begin{array}{c}\text { Skor rata-ra- } \\
\text { ta Wisatawan } \\
\text { Domestik }\end{array}$ & $\begin{array}{l}\text { Skor rata-ra- } \\
\text { ta Wisatawan } \\
\text { Mancanegara }\end{array}$ \\
\hline \multirow{3}{*}{$\begin{array}{c}\text { Pembelian } \\
\text { Ulang } \\
\text { (Y1) }\end{array}$} & Alokasi Waktu Liburan (Y1.1) & 3,90 & 4,02 \\
\hline & Alokasi Anggaran Liburan (Y1.2) & 3,68 & 3,70 \\
\hline & Rata-rata & 3,79 & $\mathbf{3 , 8 6}$ \\
\hline \multirow{7}{*}{$\begin{array}{l}\text { Komitmen } \\
\text { Merek } \\
\text { (Y2) }\end{array}$} & $\begin{array}{l}\text { Keinginan Untuk Tidak Berpindah } \\
\text { Ke DTW lain (Y2.1) }\end{array}$ & 3,18 & 2,94 \\
\hline & $\begin{array}{l}\text { Keyakinan akan Pesona DTW Ka- } \\
\text { wasan Sanur (Y2.2) }\end{array}$ & 3,00 & 3,10 \\
\hline & Ikatan Khusus (Y2.3) & 3,44 & 3,44 \\
\hline & Pemberian Kritik dan Saran (Y2.4) & 4,08 & 3,74 \\
\hline & Pemenuhan Harapan (Y2.5) & 3,92 & 3,84 \\
\hline & $\begin{array}{l}\text { Pembelaan akan Kekeliruan Infor- } \\
\text { masi (Y2.6) }\end{array}$ & 4,02 & 3,72 \\
\hline & Rata-rata & 3,60 & 3,46 \\
\hline \multirow{6}{*}{$\begin{array}{c}\text { Rekomen- } \\
\text { dasi / Getok } \\
\text { Tular } \\
\text { (Y3) }\end{array}$} & Rekomendasi Verbal (Y3.1) & 4,52 & 4,40 \\
\hline & kPernyataan Keunggulan (Y3.2) & 4,22 & 4,24 \\
\hline & Ajakan untuk Berlibur (Y3.3) & 4,28 & 4,04 \\
\hline & Deskripsi Pengalaman Positif (Y3.4) & 4,36 & 4,00 \\
\hline & Rata-rata & 4,35 & $\mathbf{4 , 1 7}$ \\
\hline & Rata-rata Umum & 4,01 & 3,75 \\
\hline
\end{tabular}

Sumber : Hasil Pengolahan Data, 2015

\section{Penutup}

Dari keseluruhan tahapan penelitian maka dapat ditarik simpulan sebagai berikut :

Pertama, dari delapan atribut destinasi wisata Kawasan Sanur yaitu: 1) keindahan alam, 2) budaya dan sejarah, 3) suasana, 4) aksesibilitas 5) keamanan, 6) biaya, 7) pelayanan, 8) olahraga dan aktivitas luar, yang memiliki pengaruh masing-masing dalam menentukan persepsi wisatawan terhadap atribut wisata di Kawasan Sanur. Atribut yang berpengaruh dominan sebagai pembentuk persepsi wisatawan di Kawasan Sanur adalah atribut suasana, dengan koefisien korelasi o,829, dengan faktor keindahan alam serta aksesibilitas pada urutan kedua dan ketiga. Hal ini dikarenakan 
tujuan sebenarnya wisatawan melakukan perjalanan ke Kawasan Sanur adalah mencari suasana (ambience) lain dari kehidupan keseharian mereka seperti ketenangan, hiburan, dan relaksasi. Wisatawan juga dapat berbaur dan berinteraksi dengan masyarakat lokal. Kawasan Sanur dinilai memiliki suasana yang sesuai bagi mereka yang menginginkan suasana tenang untuk bersantai dan berlibur.

Kedua, persepsi wisatawan terhadap atribut wisata di Kawasan Sanur adalah positif, yang berarti secara umum wisatawan mempersepsi bahwa atribut wisata di Kawasan Sanur tergolong baik dengan nilai rata-rata 3,78 dengan rata-rata tertinggi yaitu pada faktor suasana yaitu 4,12 dan faktor yang mendapatkan skor rata-rata terendah adalah faktor olahraga dan aktivitas luar dengan skor rata-rata 3,51.

Ketiga, tingkat loyalitas berkunjung wisatawan domestik maupun mancanegara ke Kawasan Sanur berada pada tingkat tinggi, yang berarti secara umum wisatawan yang mengunjungi Kawasan Sanur tergolong loyal, dengan nilai rata-rata 4,01 bagi wisatawan domestik dan 3,75 bagi wisatawan mancanegara. Loyalitas wisatawan terhadap Kawasan Sanur dengan tingkat sangat tinggi adalah berdasarkan variabel variabel rekomendasi verbal, variabel deskripsi pengalaman positif, variabel ajakan untuk berlibur serta variabel pernyataan keunggulan. Variabel rekomendasi atau getok tular menjadi variabel dengan nilai tertinggi menunjukkan bahwa pentingnya aspek rekomendasi dalam loyalitas wisatawan. Pengalaman positif yang diceritakan melalui words of mouth maupun melalui blog mampu memberikan efek positif terhadap kedatangan kerabat maupun kolega wisatawan ke Kawasan Sanur.

Berdasarkan hasil analisis yang telah dilakukan dan kesimpulan yang diperoleh maka berikut ini saran yang diberikan kepada pihak pemerintah sebagai leading sektor pengembangan pariwisata antara lain:

Pemerintah dalam merencanakan pembangunan di Kawasan Sanur hendaknya memperhatikan karakter dan budaya masyarakat setempat. Sehingga masyarakat Sanur tidak merasa asing dengan adanya produk wisata yang dihasilkan, melainkan bisa ikut merasakan dan berpartisipasi dalam mengembangkan pariwisata di daerahnya sendiri. Kearifan lokal yang telah dibangun harus dipertahankan sebagai daya tarik wisata karena Sanur merupakan daerah unik yang sesuai dengan karakter wilayah dan masyarakat setempat.

Pemerintah mencanangkan program Pantai Sanur bebas dari sampah dengan cara membuat peraturan, pelarangan, dan sanksi yang di muat di media umum di sekitar pantai berupa poster, papan informasi, memberikan sanksi yang tegas kepada siapapun yang melanggar, menyediakan penyediaan tempat sampah yang lebih banyak dan penempatannya hendaknya di tempat yang strategis. 
Selain itu juga terdapat beberapa saran yang diberikan kepada pengelola wisata di Kawasan Sanur antara lain: menjaga kualitas kebersihan dan kelangsungan kawasan pantai, seperti menyediakan fasilitas bak sampah disetiap usaha wisata sehingga tidak menimbulkan kesembrawutan dan ketidaknyamanan melakukan aktivitas di Kawasan Sanur. Penataan usaha-usaha penunjang wisata. Usaha-usaha penunjang berkembang pesat, bermacam jenis usaha akomodasi, restoran, bar, art shop semakin memenuhi pesisir pantai demikian warung-warung emperan dan pedagang kaki lima semakin liar membuka lapak di beberapa bagian pantai, sehingga para pengelola usaha wisata wajib mengelola fasilitas umum di kawasan Sanur agar tidak merusak SDA dan kegiatan wisata bahari pantai serta mengurangi gesekan berbagai macam kepentingan.

Penelitian ini merupakan penelitian awal yang berkaitan dengan persepsi wisatawan terhadap atribut wisata di kawasan Sanur serta pengaruhnya terhadaployalitas berkunjung wisatawan, tentunya masih banyakkekurangan dan memerlukan penyempurnaan. Bagi peneliti lainnya di masa mendatang, agar dapat meneliti lebih dalam dan mengembangkan penelitian pada sisi perspektif wisatawan pengelola wisata, perizinan dan strategi pemasaran wisata di daerah wisata Sanur maupun daerah wisata lainnya seperti Kuta, Ubud dan Nusa Dua.

\section{Ucapan Terima Kasih}

Untuk yang pertama dan terutama penulis mengucap syukur dan terima kasih kepada Tuhan Yesus Kristus atas penyertaan-Nya selama penulis menyelesaikan penelitian ini. Kedua orangtua, I Nengah Netera dan Kustini juga keluarga kecilku dan adik-adik tersayang atas cinta kasih dan dukungannya yang sangat berarti dan menguatkan penulis sehingga dapat menyelesaikan penelitian ini. Artikel ini merupakan ringkasan tesis yang dibuat dengan saran dari pembimbing dan pihak lainnya. Pada kesempatan ini penulis hendak menyampaikan terima kasih sebesar-besarnya kepada Prof. Dr. Ir. Made Antara, MS. selaku pembimbing I dan Dr. I Nyoman Madiun,M.Sc. selaku pembimbing II atas waktu, perhatian, semangat dan kesabarannya dalam memberikan bimbingan, masukan, koreksi dan saran yang sangat membantu penulis dalam penyusunan dan penyelesaian tesis ini. Ucapan terima kasih disampaikan juga kepada para dosen penguji yaitu Prof. Dr. I Nyoman Sirtha, SH.,MS., Prof. Made Sudiana Mahendra, MApp. Sc.PhD., Prof. Dr. I Nyoman Darma Putra, M.Litt., dan Dr. Ir. Syamsul Alam Paturusi, MSP. yang telah banyak memberikan perhatian, kritik dan saran demi kesempurnaan tesis ini.

\section{Daftar Pustaka}

Dann. 1977. Anomie, Ego-Enhancement and Tourism. Annals of Tourism Research. 
Vol.2 No.5, pp.72-87.

Darmaningsih, Popong Nurhayati dan Anna Fatchiya, 2006. Tingkat Kepuasan Pengunjung Objek Wisata SEA WORLD INDONESIA. Buletin Ekonomi Periklanan, Vol. VI. No. 2

Dharmmesta, B.S. 1999. Loyalitas Pelanggan: Sebuah Kajian Konseptual Sebagai Panduan Bagi Peneliti. Jurnal Ekonomi dan Bisnis Indonesia.Vol 14 No. 3, pp. 73-88.

Dick, A. and Basu, K., 1994. Customer Loyalty: Towards An Integrated Framework. Journal of the Academy of Marketing Science Vol. 22 No. 2, pp. 99-113.

Kozak, Metin and Mike Rimmington. 1999. Measuring Tourist Destination Competitiveness: Conceptual Considerations And Empirical Findings. Hospitality Management, Vol. 18 No.1, pp. 273-283.

Lovelock, C.H., Wirtz, J. dan Chatterjee, J. 2007. Service Marketing: People, Technology, Strategy. Sixth Edition. USA: Prentice Hall.

Lovelock, C.P. Patterson, dan R. Walker. 2001. Services Marketing: An Asia Perspective. Sydney : Pearson Education.

Meng, Fang.,Tepanon, Yodmanee., dan Uysal, Muzaffer. 2006. Measuring Tourist Satisfaction by Attribute and Motivation: The Case of Nature Based Resort. Journal of Vacation Marketing. Vol. 8 No.2, pp. 263-272.

Morgan, R.M., \& Hunt. S.D.,1994. The Commitment-Trust of The Relationship Marketing. Journal of Marketing, July, Vol. 58, No.3, pp.20-38.

Paliati, A. Lida. 2007. Analisis Pengaruh Nilai Pelanggan, Kepuasan Terhadap Loyalitas Nasabah Tabungan Perbankan Di Sulawesi Selatan, http://puslit2. petra.ac.id/ejournal/index.php/man/article/viewArticle/16637

Parasuraman, A. dkk. 1988. Servqual: A Multiple-Item Scale for Measuring Consumer Perception of Service Quality. Journal of Retailing, Vol. 64. pp 12-40.

Picard, Michael, 2006. Pariwisata Budaya dan Budaya Pariwisata. Jakarta: Kepustakaan Populer Gramedia.

Rangkuti, Freddy. 2003. Measuring Customer Satisfaction, Teknik Mengukur Dan Strategi Meningkatkan Kepuasan Pelanggan Plus Analisis Kasus PLN-JP. Jakarta: Gramedia Pustaka Utama.

Walgito, B. 2002. Pengantar Psikologi Umum. Edisi Revisi. Cetakan Keempat. Yogyakarta: Andi Offset

Zhou, Lichen. 2005. Destination attributes that attract international tourists to Cape Town. Masters Thesis. University of Western Cape. South Africa 


\section{Profil Penulis}

Ni Luh Ayu Nusantini, S.Psi, Psikolog. Menyelesaikan studi masternya di Program Studi Magister Kajian Pariwisata Universitas Udayana tahun 2015. Ia menyelesaikan program studi S1 pada tahun 1996 di Fakultas Psikologi Jurusan Monoprogram Universitas 17 Agustus 1945 Surabaya. Ia juga telah mengikuti Pelatihan Psikodiagnostika di Semarang pada tahun 2002 guna memenuhi persyaratan untuk mendapat sebutan Psikolog dan Ijin Praktek Psikologi. Tahun 2006 ia diangkat sebagai Pegawai Negeri Sipil di lingkungan Pemerintah Daerah Kabupaten Gianyar dan bertugas pada Badan Kepegawaian Daerah dan tahun 2008 bertugas di Bagian Humas dan Protokol Kabupaten Gianyar. Sejak Bulan Juni Tahun 2009 pindah tugas ke lingkungan Pemerintah Provinsi Bali dan bertugas pada unit Kerja Badan Kepegawaian Daerah. Bulan Februari 2014 hingga saat ini bertugas pada unit Kerja Dinas Pendapatan Daerah Provinsi Bali di Unit Pelayanan Terpadu (UPT) Kota Denpasar. 